\title{
МОЖЛИВОСТІ АНАЛІЗУ ВАРІАБЕЛЬНОСТІ РИТМУ СЕРЦЯ В ДІАГНОСТИЦІ ЕМОЦІЙНОГО СТАНУ ЛЮДИНИ
}

\author{
І. Чайковський ${ }^{1}$, В. Калниш ${ }^{2}$, Т. $\epsilon_{н a^{2}}$, А. $\Theta_{н a^{2}}$, Ю. Вировий ${ }^{3}$, М. Кетько \\ Ю. Фролов ${ }^{5}$, В. Будник ${ }^{5}$ \\ Міжнародний науково-навчальний центр ITіC НАН України', \\ Інститут медицини праці НАМН України", Експертна група "Kwendi" \\ TOB «IMECK» ${ }^{4}$ Інститут кібернетики НАН України ${ }^{5}$
}

\begin{abstract}
Представлено використання методу оцінки емоційного стану людини, що придатний до використання на робочому місці, на основі аналізу варіабельності ритму серця.

Обстежено 28 здорових добровольців. Кожному з них на дисплеї персонального комп'ютера послідовно було показано 3 аудіовізуальні кліпи. Один з них містив інформацію, що викликає позитивні емоції, другий - негативні, третій був нейтральним. За показниками ВРС з допомогою одно- і багатовимірного ЛДА проаналізовані усі можливі пари емоційних станів.

Перегляд емоційно забарвлених відеокліпів (обох знаків) викликає достовірне уповільнення частоти серцевих скорочень, а також деяке зменшення варіабельної ритму серця. Негативні емоції викликають, крім того, регуляризацію, спрощення структурної організації ритму серця. Точність дискримінації пари "відпочинок - емоційний відеокліп" склала 91 \%; пари "емоційний відеокліп - нейтральний відеокліп" - 98 \% ; пари "відпочинок - нейтральний відеокліп" - 74 \% ; пари "позитивний відеокліп - негативний відеокліп" - 91 \% .

Аналіз варіабельності ритму серця дає можливість з високою достовірністю визначати емоційний стан обстежуваного на робочому місці.
\end{abstract}

Ключові слова: варіабельність ритму серця, позитивні емоції, негативні емоції, лінійний дискримінантний аналіз, нелінійна динаміка.

\section{ВОЗМОЖНОСТИ АНАЛИЗА ВАРИАБЕЛЬНОСТИ РИТМА СЕРДЦА В ДИАГНОСТИКЕ ЭМОЦИОНАЛЬНОГО СОСТОЯНИЯ ЧЕЛОВЕКА}

\author{
И. Чайковский ${ }^{1}$, В. Калныш ${ }^{2}$, Т. Ена ${ }^{2}$, А. Ена ${ }^{2}$, Ю. Выровой ${ }^{3}$, М. Кетько \\ Ю. Фролов ${ }^{5}$, В. Будник \\ Международный научно-учебный центр ИТиС НАН Украины', \\ Институт медицины труда НАМн Украины ${ }^{2}$, Экспертная группа «Kwendi»", \\ ООО "ИМЕСК»", Институт кибернетики НАН Украины ${ }^{5}$
}

\begin{abstract}
Представлено использование метода оценки эмоционального состояния человека, пригодного для использования на рабочем месте, на основе анализа вариабельности ритма сердца.

Обследовано 28 здоровых добровольцев. Каждому из них на дисплее персонального компьютера последовательно было показано 3 аудиовизуальных клипа. Один из них содержал информацию, вызывающую положительные эмоции, второй - отрицательные, третий был нейтральным. По показателям ВРС с помощью одно- и многомерного ЛДА проанализированы все возможные пары эмоциональных состояний.

Просмотр эмоционально окрашенных видеоклипов (обоих знаков) вызывает достоверное замедление частоты сердечных сокращений, а также некоторое уменьшение вариабельности сердечного ритма. Негативные эмоции вызывают, кроме того, регуляризацию, упрощение структурной организации ритма сердца. Точность дискриминации пар: «эмоциональный видеоклип - нейтральный видеоклип» - 98 \%, «отдых - нейтральный» - 74 \%, «позитивный - негативный» - $91 \%$.

Анализ вариабельности ритма сердца дает возможность с высокой достоверностью определять эмоциональное состояние обследуемого на рабочем месте.
\end{abstract}

Ключевые слова: вариабельность ритма сердца, позитивные эмоции, негативные эмоции, линейный дискриминантный анализ, нелинейная динамика.

(C) І. Чайковський, В. Калниш, Т. Єна та ін. 


\title{
VALUE OF HEART RATE VARIABILITY ANALYSIS IN DIAGNOSTICS OF THE EMOTIONAL STATE
}

\author{
I. Chaykovskyi ${ }^{1}$, V. Kalnysh ${ }^{2}$, T. Yena ${ }^{2}$, A. Yena ${ }^{2}$, Yu. Vyrovyi ${ }^{3}$, M. Ketko ${ }^{4}$, Yu. Frolov ${ }^{5}$, \\ V. Budnyk
}

\author{
International Research and Training Center of NAS of Ukraine', \\ Institute of Occupational Medicine", Expert Group "Kwendi" "I, "IMESK" Ltd. ${ }^{4}$, \\ Institute of Cybernetics of NAS of Ukraine ${ }^{5}$
}

The is presented the development of method for evaluation of emotional state of man, what suitable for use at the workplace based on analysis of heart rate (HR) variability.

28 healthy volunteers were examined. 3 audiovisual clips were consistently presented on the display of the personal computer for each of them. One clip contained information originating the positive emotions, the second one - negative emotions, the third one - neutral. All possible pairs of the emotional states were analysed with help of one- and multidimensional linear discriminant analysis based on HR variability.

Showing the emotional video-clips (of both signs) causes reliable slowing of HR frequency and also some decreasing of HR variability. In addition, negative emotions cause regularizing and simplification of structural organization of heart rhythm. Accuracy of discrimination for pair "emotional - neutral" video clips was $98 \%$, for pair "rest - neutral" was $74 \%$, for pair "positive - negative" was $91 \%$.

Analysis of HR variability enables to deter mine the emotional state of ob served person at the workplace with high reliability.

Key words: heart rate variability, positive emotions, negative emotions, linear discriminant analysis, nonlinear dynamics.

Вступ. Об'єктивна діагностика емоційного відгуку на різноманітні зміни довкілля на підставі аналізу різних фізіологічних сигналів є галуззю наукових досліджень, що інтенсивно розвивається. На сьогодні не існує загальноприйнятого визначення поняття " емоція". Нам найбільш вдалим здається визначення емоції як процесу, який відображає суб'єктивне оціночне відношення до існуючих або можливих ситуацій $з$ точки зору сприятливого (позитивні емоції) або несприятливого (негативні емоції) впливу цих ситуацій на виживання індивіда [1].

Емоції містять значну фізіологічну складову, що має на меті підготовку організму до певної діяльності. Ця складова реалізується головним чином через вегетативну нервову систему. Оцінка реакції на стимули, що викликають позитивні або негативні емоції, особливо важлива в практиці медицини праці, оскільки дозволяє оптимізувати психічне навантаження, що виникає в процесі трудової діяльності.

Методи об'єктивної оцінки змін емоційного стану можна умовно поділити на 2 групи - прямі, пов'язані безпосередньо з оцінкою процесів, що відбуваються в центральній нервовій системі, і непрямі, засновані на оцінці діяльності вегетативної нервової системи. До першої групи належать відносно технічно складні електроенцефалографія, магнітоенцефалографія і функціональний МРТ. Друга група, передусім, представлена варіабельністю ритму серця (ВРС).

Оцінка варіабельності ритму серця широко застосовується для оцінки функціонального стану в медицині праці і спортивній медицині, а також в клінічній кардіології [2]. Нам відомі лише окремі роботи щодо застосування аналізу ВРС для оцінки емоційного стану $[3,4]$.

Метою роботи $є$ розроблення методу оцінювання позитивних і негативних емоцій, що придатний для використання на робочому місці, на основі аналізу варіабельності ритму серця.

Матеріали і методи. Обстежено 28 здорових добровольців (середній вік 22 роки). Для оцінки відтворюваності результатів 13 з них були обстежені повторно наступного дня. Дослідження проводилося таким чином: після 6-хвилинного періоду адаптації кожному обстежуваному на дисплеї персонального комп'ютера було послідовно показано 3 аудіовізуальні кліпи тривалістю 7-8 хвилин кожен. Один 3 них містив інформацію, що викликає позитивні емоції, другий негативні, третій був нейтральним. Послідовність кліпів була довільною. Слід зазначити що підбір відеоматеріалів, які стимулюють позитивні і негативні емоції, представляв певну проблему. Ми не могли скористатися базою відео- і аудіоматеріалів Humaine, яка призначена для цих цілей, оскільки усі кліпи, що містяться в ній, використовують вербальний компонент, але жоден $з$ цих кліпів не $є$ російсько- чи україномовним. Тому ми використали іншу, менш відому базу відеокліпів FilmStim [4], матеріали якої також використовувалися в психологічних і психофізіологічних дослідженнях, наприклад в роботі A. Gracanin iз співавторами [6]. Кліп, який стимулює негативні емоції, не містив вербального компонента і зображав ампутацію кінцівок і страту на електричному 
стільці. Кліпи, які стимулюють позитивні емоції були узяті авторами бази FilmStim з франкомовної кінокомедіï "Les Visiteurs", тому ми не могли скористатися ними безпосередньо. Проте нами був використаний той же підхід - в якості стимулу позитивних емоцій досліджуваним показували епізоди з кінокомедії "Іван Васильович змінює професію" Л. Гайдая, контекст якої дуже схожий на контекст фільму "Les Visiteurs". Структура нейтрального кліпу була заснована на підході Gross та Levenson [7]. Досліджуваним було показано кліп без вербального компонента, що містить зображення декількох географічних ландшафтів і фауни.

Між кліпами передбачалися періоди відпочинку тривалістю 8-10 хвилин. Аналіз варіабельності ритму серця проводився за ЕКГ в 3-х відведеннях, зареєстрованих за допомогою системи холтерівського моніторингу ECGpro компанії IMESC, Київ. Для оцінки аналізу варіабельності ритму серця нами був розроблений оригінальний пакет програм, що дозволяє розраховувати як звичайні статистичні, геометричні і спектральні характеристики, так і значну кількість показників нелінійної динаміки.

Всього розраховувалося 48 показників варіабельності ритму серця.

Крім того, оцінювалися деякі амплітудно-часові показники електрокардіосигналу, такі як амплітуди зубців R i T, тривалість комплексу QRS, інтервалів QT i PQ, симетрія зубця T.

Усі перелічені параметри розраховували для кожного стану, а саме: відпочинок, перегляд емоційно забарвлених кліпів (як обох типів разом, так і окремо таких, що викликають позитивні і негативні емоціі), перегляд нейтрального кліпу. Крім того, значення всіх показників для позитивного і негативного кліпу усереднювались $з$ метою оцінки емоційного стану незалежно від знаку емоцій.

Для того, щоб виключити вплив внутрішньогрупового розкиду індивідуальних значень, усі параметри були нормовані на значення в стані відпочинку, тобто всі значення параметрів у цьому стані приймали за $100 \%$.

Потім були проаналізовані всі можливі пари станів (а саме відпочинок - емоційний відеокліп - пара 1; емоційний відеокліп - нейтральний відеокліп - пара 2 ; відпочинок - нейтральний відеокліп - пара 3 ; позитивний відеокліп - негативний відеокліп - пара 4) 3 допомогою одно- і багатовимірного лінійного дискримінантного аналізу (ЛДА). Спочатку проводили одновимірні, а потім багатовимірні ЛДА-тести для набору параметрів, впорядкованих за спаданням по- тужності дискримінації одновимірних тестів. В результаті для кожної пари станів були отримані набори параметрів, які давали максимум достовірності дискримінації.

Результати. У всіх обстежених на електрокардіограмі не було виявлено патологічних змін, як у початковому стані так і під час тестування. У одного обстеженого при перегляді негативно забарвленого ролика було зафіксовано синкопальний стан.

У таблиці 1 для кожної з пар станів наведено результати дискримінації по 5-ти параметрах ВРС що демонструють найбільшу потужність дискримінації при одновимірному ЛДА.

У таблиці 2 наведена описова статистика для параметрів ВРС, використаних в таблиці 1 .

В табл. 3 представлені результати багатовимірного ЛДА.

Як видно з таблиці 1, параметри варіабельності ритму серця істотно відрізняються в період перегляду емоційно забарвлених кліпів і в період відпочинку. Також високо достовірні відмінності існують між фазами перегляду емоційно забарвлених і нейтральних кліпів. При цьому в обох випадках найбільша дискримінуюча здатність при одновимірному ЛДА (89,7 \% і 88,9 \% відповідно) була продемонстрована таким показником як Середній_RR, тобто частота серцевих скорочень. Під час перегляду емоційно забарвлених кліпів вона достовірно знижувалася.

Наступними за силою дискримінації параметрами були в обох випадках такі близькі статистичні параметри варіабельності ритму, як Мo, CV, PNN50, PNN20, SDNN. При цьому при перегляді емоційно забарвленого відеокліпу загальна варіабельність ритму дещо зменшувалась, як видно із таблиці 2. При розділенні станів, що виникають при перегляді кліпів, що викликають емоції протилежних знаків, найбільшу дискримінаційну потужність продемонстрував показник FDDA, Також відносно високу дискримінаційну потужність продемонстрували спектральні показники ВРС.

Багатовимірний ЛДА, представлений в таблиці 3, дозволив розділити стани перегляду емоційного відеокліпу із станами відпочинку і перегляду нейтрального кліпу з точністю 91 \% і 98 \% відповідно. У парі відпочинок-нейтральний відеокліп максимальна потужність одновимірного ЛДА була $71 \%$, а багатовимірного - 74 \%. Достовірної зміни частоти серцевих скорочень між цими станами виявлено не було. Точність розділення станів, що виникають при перегляді кліпів, які викликають емоції протилежних знаків, склала $91 \%$. 
Таблиця 1. Потужність дискримінації пар станів для показників ВРС, що маютьнайкращу дискримінаційну здатність

\begin{tabular}{|l|c|c|c|c|}
\hline \multirow{4}{*}{ Параметри } & \multicolumn{3}{|c|}{ Дискримінаційна потужність для пар станів, \% } \\
\cline { 2 - 5 } & пара 1 & пара 2 & пара 3 & пара 4 \\
\hline Середній RR & $\begin{array}{c}\text { відпочинок - } \\
\text { емоційний відеокліп }\end{array}$ & $\begin{array}{c}\text { емоційний відеокліп } \\
\text { нейтральний } \\
\text { відеокліп }\end{array}$ & $\begin{array}{c}\text { відпочинок - } \\
\text { нейтральний } \\
\text { відеокліп }\end{array}$ & $\begin{array}{c}\text { позитивний } \\
\text { відеокліп - } \\
\text { негативний відеокліп }\end{array}$ \\
\hline Mo & 89,7 & 88,9 & - & - \\
\hline CV & 83,3 & 81,8 & - & - \\
\hline PNN20 & 83,1 & - & 71 & - \\
\hline Samp En & 80,8 & 74,8 & 58,9 & - \\
\hline PNN50 & 79,8 & - & 69,9 & - \\
\hline SDNN & - & 78,2 & 69,9 & 75,9 \\
\hline FDDA & - & 75,6 & - & 68,8 \\
\hline MF & - & - & - & 64,3 \\
\hline CC0 & - & - & - & 62,6 \\
\hline LF HF & - & - & - & 62,6 \\
\hline LF & - & - & & - \\
\hline
\end{tabular}

Примітка: Середній_RR - середнє значення інтервалів RR; Mo - мода; CV - коефіцієнт варіації; SDNN - стандартне відхилення NN інтервалів; PNN50 - відсоток NN50 (тобто кількості пар послідовних інтервалів RR, що розрізняються більш ніж на 50 мс) від загальної кількості послідовних пар інтервалів; PNN20 - відсоток NN20 (тобто кількості пар послідовних інтервалів RR, що розрізняються більш ніж на 20 мс) від загальної кількості послідовних пар інтервалів; CC0 - час в мс зсуву автокореляційної функції до отримання значення коефіцієнта кореляції менше нуля; MF - потужність спектра в діапазоні 0,08-0,15 Гц; LF - потужність спектра в діапазоні 0,01-0,08 Гц; LF_HF - співвідношення потужності спектра в діапазоні 0,01-0,08 Гц до потужності спектра в діапазоні 0,15-0,5 Гц; $\mathrm{Samp}$ En - ентропія шаблонів; FDDA - фрактальна розмірність по дисперсійному аналізу.

Таблиця 2. Описова статистика показників ВРС, що мають найкращудискримінаційну здатність

\begin{tabular}{|c|c|c|c|c|c|}
\hline \multirow[b]{2}{*}{ Параметри } & \multicolumn{5}{|c|}{ Значення нормованих параметрів, $\mathrm{M} \pm \mathrm{m}$} \\
\hline & відпочинок & $\begin{array}{c}\text { нейтральний } \\
\text { відеокліп }\end{array}$ & $\begin{array}{c}\text { позитивний } \\
\text { відеокліп }\end{array}$ & $\begin{array}{c}\text { негативний } \\
\text { відеокліп }\end{array}$ & емоційний відеокліп \\
\hline Середній RR & 100 & $103 \pm 7$ & $118 \pm 7$ & $116 \pm 9$ & $117 \pm 8$ \\
\hline Mo & 100 & $104 \pm 7$ & $113 \pm 9$ & $110 \pm 5$ & $112 \pm 7$ \\
\hline $\mathrm{CV}$ & 100 & $95 \pm 4$ & $90 \pm 9$ & $92 \pm 7$ & $91 \pm 9$ \\
\hline PNN20 & 100 & $97 \pm 5$ & $87 \pm 8$ & $86 \pm 10$ & $87 \pm 9$ \\
\hline Samp En & 100 & $103 \pm 8$ & $111 \pm 10$ & $108 \pm 7$ & $109 \pm 8$ \\
\hline PNN50 & 100 & $98 \pm 5$ & $86 \pm 7$ & $90 \pm 10$ & $88 \pm 9$ \\
\hline SDNN & 100 & $97 \pm 8$ & $91 \pm 8$ & $88 \pm 9$ & $89 \pm 9$ \\
\hline FDDA & 100 & $97 \pm 10$ & $107 \pm 11$ & $95 \pm 7$ & $101 \pm 9$ \\
\hline MF & 100 & $96 \pm 9$ & $109 \pm 9$ & $95 \pm 10$ & $102 \pm 10$ \\
\hline $\mathrm{CC} 0$ & 100 & $101 \pm 7$ & $97 \pm 8$ & $104 \pm 6$ & $100 \pm 6$ \\
\hline LF HF & 100 & $107 \pm 12$ & $95 \pm 13$ & $102 \pm 8$ & $98 \pm 10$ \\
\hline LF & 100 & $104 \pm 8$ & $97 \pm 10$ & $104 \pm 10$ & $99 \pm 10$ \\
\hline
\end{tabular}

Таблиця 3. Результати багатовимірного ЛДА для всіх пар станів

\begin{tabular}{|l|c|c|c|c|}
\hline \multicolumn{1}{|c|}{ Пари станів } & Пара 1 & Пара 2 & Пара 3 & Пара 4 \\
\hline Максимальна дискримінаційна потужність, \% & 91 & 98 & 74 & 91 \\
\hline $\begin{array}{l}\text { Кількість параметрів, які забезпечують максимальну } \\
\text { дискримінаційну потужність }\end{array}$ & 9 & 20 & 19 & 41 \\
\hline
\end{tabular}

Обговорення. Управління психічним навантажен ням $є$ найважливішим завданням при створенні сучасних автоматизованих робочих місць людини-оператора. В зв'язку з цим $є$ сенс чітко визначити по- няття "психічне навантаження". Незважаючи на широкий спектр використання, на сьогодні не існує загальноприйнятого визначення терміну "психічне навантаження" [8]. Згідно з опублікованим в 1991 році 
стандартом Міжнародної організації зі стандартизації, психічне навантаження відноситься до робочого оточення і характеризується комплексом чинників, який впливає на індивіда в процесі діяльності: зміст завдання, технічні засоби (обладнання, автоматика), фізичні і соціальні умови. Психічне навантаження викликає психічну напругу [9]. У свою чергу, в психічній напрузі виділяють когнітивну складову (обумовлену об'єктивним змістом завдання, наприклад, числом контрольованих параметрів) [10] і емоційну (відображає вірогідність помилкової дії, значущість наслідків помилки і результату діяльності для індивіда) [11]. Очевидно, що без оцінки емоційного відгуку на поставлені завдання, неможливо адекватно оцінити міру психічної напруги. У нашому дослідженні показано, що найінформативнішим параметром для розділення станів спокою і емоційної напруги виявився такий легко контрольований показник, як частота серцевих скорочень, яка зменшується під час перегляду емоційно забарвлених кліпів (тоді як під час перегляду нейтрального кліпу вона достовірно не змінювалася). На нашу думку, причиною цього феномену є активація парасимпатичної нервової системи (блукаючого нерва) внаслідок концентрації уваги на тому, що відбувається на екрані. Подібний ефект описаний раніше в роботі [12]. Слід зазначити, що незважаючи на подовження середнього інтервалу RR відзначалось зменшення варіабельності ритму серця, яке вірогідно свідчить про збільшення активності вищих рівнів регуляції, що парадоксальним чином поєднується з активацією парасимпатичного відділу ВНС. Як було показано, багатовимірний ЛДА дозволив розділити стани перегляду емоційно забарвленого відеокліпу із станами відпочинку і перегляду нейтрального кліпу з високою точністю. Слід сказати, що в другій парі станів дискримінаційна потужність була помітно більшою, ніж у першій - 98 \% проти 91 \%. На наш погляд, це пояснюється тим, що фаза відпочинку включала період перед початком виконання завдання (ситуація очікування - антиципаціі), тобто не була повністю вільна від психічної напруги.

Інший, в порівнянні з попередніми парами станів, набір параметрів продемонстрував найбільшу дискримінаційну потужність при розділенні станів при перегляді емоційних кліпів протилежних знаків.

Найбільш цінний показник фрактальної розмірності по дисперсійному аналізу (FDDA) належить до сімей ства параметрів найсучаснішої області аналізу варіабельності ритму серця, що швидко розвивається, а саме до оцінки ступеня "хаотичності" ритму за допомогою теорії нелінійних динамічних систем. Ця тео- рія показує, що поведінка динамічної системи може бути більш або менш хаотичною, тобто складною, непередбачуваною. Чим більш непередбачувана система, тим більше зв'язків усередині неї, тим вона стійкіша до зовнішніх збурень, тим вона більш адаптована до стресу. Достовірне зменшення вираженості фрактальної структури під впливом негативних емоцій свідчить про регуляризацію, спрощення структурної організації сигналу. Також відносно високу дискримінаційну потужність продемонстрували спектральні показники ВРС, що збігається з результатами, отриманими R. McCraty із співавторами [13]. При багатовимірному ЛДА також вдалося розділити ці стани 3 високою точністю, проте лише за допомогою великого числа параметрів. Слід зазначити, що основні статистичні показники варіабельності ритму серця не продемонстрували достовірних відмінностей під час перегляду роликів з різною емоційною забарвленістю. Вірогідно, механізми реакції на протилежні за знаком емоційні стимули тонші i, поза сумнівом, заслуговують подальшого вивчення.

Слід також зазначити, що досліджені нами амплітудно-часові показники електрокардіограми не показали задовільної дискримінаційної здатності ні для однієї з пар станів. Це дещо суперечить результатам, отриманим в нашій ранній роботі [14], у якій показано, що симетрія зубця Т електрокардіограми $є$ чутливим індикатором стресу, спровокованого публічним виступом перед аудиторією.

В зв'язку з цим слід зазначити, що стрес і емоційний відгук, які в літературі часто не розділяються, не тотожні один одному.

Стресова ситуація, пов'язана з необхідністю активних дій людини, що досліджується, викликає значно більшу психічну напругу, ніж пасивне переживання, викликане переглядом відеокліпу. Відповідно, і механізми адаптації в цих ситуаціях, мабуть, розрізняються. При перегляді відеокліпу задіяно лише хронотропний механізм, що проявляється в зміні частоти серцевих скорочень і варіабельності серцевого ритму. При стресі, який спровокований публічним виступом, включається також і інотропний механізм, пов'язаний із зміною сили серцевих скорочень, непрямим проявом чого є тонка зміна форми окремих елементів електрокардіограми.

Висновок. Аналіз варіабельності ритму серця дає можливість 3 високою достовірністю визначати емоційний стан обстежуваного на робочому місці. Перегляд емоційно забарвлених відеокліпів (обох знаків) викликає достовірне уповільнення частоти серцевих скорочень, що обумовлено активізацією парасимпа- 
тичної частини вегетативної нервової системи, а також деяке зменшення варіабельної ритму серця.

\section{Лiтература}

1. Payne E.F. Definition of emotions E.F. Payne// Journal of BEM. - 2003. Vol.4, № 3, - P. 38-43.

2. Анализ вариабельности сердечного ритма при использовании различных электрокардиографических систем / Баевский Р.М., Иванов Г.Г., Чирейкин Л.В. и др. // Вестник аритмологии. - 2001. № 24. - С. 65-87.

3. The Effects of Emotions on Short-Term Power Spectrum Analysis ofHeart Rate Variability / Rollin McCraty, Mike Atkinson, William Tiller, Glen Rein, and Alan D. Watkins // American Journal of Cardiology. - 1995. V76. № 14. - P. 1089-1093.

4. Using Neural Network to Recognize Human Emotions from Heart Rate Variability / C. K. Lee, S. K. Yoo, Y. J. Park [et. al.]/ / IEEE Engineering in Medicine and Biology Society (IEEEEMBS), 2005. - P. 5523-5525.

5. Schaefer A., Philippot P. Assessing the effectiveness of a large database of emotion-eliciting films: A new tool for emotion researchers. A. Schaefer, F. Nils, X. Sanchez, /Cognition and Emotion. - 2010. - Vol. 24. №7. P. 1153-1172.

6. Gracanin A. Relations between dispositional expressivity and physiological changes during acute positive and negative affect A. Gracanin, I. Kardum, J. Hudek-Knezevic / Psychological Topics 1. - 2007. - Vol.2, P.311-328.

7. Gross J. J. Emotion elicitation using films J. J. Gross, R. W. Levenson / Cognition and Emotion. - 1995. - Vol.9. P.87-108.

8. Машин В. А. Психическая нагрузка, психическое напря-
Негативні емоції викликають регуляризацію, спрощення структурної організації ритму серця.

жение и функциональное состояние операторов систем управления // Вопросы психологии. - 2007, № 6. - С. 86-96. 9. Міжнародний стандарт ISO 10075-1:1991. Эргономические принципы, относящиеся к нагрузке при умственной деятельности: Общие термины и их определения.

10. Kramer A. F. Physiological metrics of mental workload: A review of recent progress // Damos D. L. (Ed.) Multiple-Task performance. London: Taylor and Francis, 1991. - P. 279-328. 11. Myrtek M., Brugner G., Muller W. Validation studies of emotional, mental and physical workload components in the field // Fahrenberg J., Myrtek M. (Eds.) Ambulatory assessment. Computer-assisted psychological and psychophysiolo-gical methods in monitoring and field studies. Seattle, WA: Hogrefe \& Huber, 1996. - P. 287-304.

12. Richards $\mathrm{J}^{\mathrm{E}} \mathrm{E}^{\wedge}$ Casey B.J. Heart rate variability during attention phases attention phases in young infants // Psychophysiology. - 2001, № 6. - C. 86-96.

13. The impact of a new emotional self-management program on stress, emotions, heart rate variability, DHEA and cortisol / McCraty R., Barrios-Choplin B., Rozman D., Atkinson M., Watkins A. // Integrative Physiological and Behavioral Science. - 1998. Vol. 33. № 2. - p. 151-170.

14. Chaikovsky I. Intraindividual variability of T-wave shape on electrocardiogram as indicator of stress // Proc. of 33-rd international congress on electrocardiology (Koln, Germany) - 2006. - p. 28. 